ISSN 1112-9867

http://www.jfas.info

\title{
AUTOMATED ATTENDANCE MANAGEMENT AND ALERT SYSTEM
}

S. K. N. A. Rahim ${ }^{1, *}$, N. R. P. Ismail ${ }^{2}$, F. A. Razak ${ }^{2}$, I. Z. Zulkifli ${ }^{2}$, N. H. Jamian ${ }^{2}$, N. F. Razi ${ }^{2}$ and N. H. Mohammad ${ }^{2}$

${ }^{1}$ Faculty of Computer and Mathematical Sciences, UniversitiTeknologi MARA, 40450 Shah Alam, Selangor, Malaysia.

${ }^{2}$ Faculty of Computer and Mathematical Sciences, UniversitiTeknologi MARA, 35600Tapah, Perak, Malaysia

Published online: 10 November 2017

\begin{abstract}
"Automated Attendance Management and Alert System (AAMAS)" was developed to help UiTM lecturers and Academic Affairs Department in monitoring students' absenteeism and improving the absenteeism record management. AAMAS provides various functions, from managing and recording students' attendance record, to sending automatic alerts to students with high absenteeism via short messaging system (SMS) and email. The system is also able to track the number of alerts sent. Through AAMAS, a significant amount of time and money can be saved, for instance time needed to fill out forms and issue notification letters manually can be minimized significantly. Besides, message interception, human resources and human errors can also be reduced. AAMAS which was tailored to UiTM could be also enhanced and custom-made to cater other learning institutions' requirements throughout Malaysia.
\end{abstract}

Keywords: automated system; attendance management; system development.

Author Correspondence, e-mail: sitik781@salam.uitm.edu.my

doi: http://dx.doi.org/10.4314/jfas.v9i6s.6 


\section{INTRODUCTION}

Nowadays, absenteeism from lectures by the university students appears to be a serious problem. According to [1], it shows that there is a significant positive relationship between attendance to class and university student's performance. This indicates that university students who come to class more frequently will have better results. Absenteeism not only leads to low academic achievements, but may also contribute to high dropout rates.

In UniversitiTeknologi MARA (UiTM), whenever a student reaches 20\% absenteeism from the total contact hours for a particular course, he or she can be barred from sitting the final examination by the Academic Affairs Division (HEA) [2]. In the current practice, students will be given verbal reminder by their lecturers if they failed to attend two sessions of classes without any valid reason. Then, the respective guardians will get a notification letter issued by HEA once the absenteeism reaches $10 \%$. Later, when it reaches $20 \%$, another notification letter will be issued which requests the student to submit a show cause letter. A failure to do so may result in the student being barred from sitting the final examination.

There are cases where parents or guardians raised an issue that they were not being notified or they received late notifications regarding the absenteeism of their children. Currently, the notification is being sent out by snail mail to the students' registered address. The possible cause of notifications delivery failure could be due to change of address or the students themselves receive the letter and did not forward it to the parents.

In UiTM, the process to keep track of students' attendance is done manually by each lecturer teaching a specific course. Every time a student comes to class, he or she will need to put down her signature on the attendance sheet as a proof of attending the class. The lecturers need to calculate the percentage of absenteeism of the students in order to identify students that reach certain percentages. This process is tedious, especially for a large number of students. This will take times and lots of work to flips the entire attendance list for every student.

According to [2], lecturer has to record the students' attendance, then identify students whose absenteeism rate that reach $10 \%$ and $20 \%$ which the names will be submitted to the Academic Affairs Division. Next, notification letter to students and guardians will be issued by Deputy Registrar (Academic). The long process taken may cause delays in the receiving of the 
notifications by the students and guardians.Hence, the aim of sending the notifications to alert both students and guardians will not be attained. It has been observed that the absence of a system, limits any automated process that could have been done by the system to facilitate the management in managing and recording the student's attendance and sending notifications to the lecturers, students and guardians.

As mobile phone is almost considered as one compulsory gadget for university students, there is a great potential to utilize short message service (SMS) reminders for developing an automated system to improve students' attendance in university. SMS reminder have a number of characteristics that make it suitable to be used as an attendance alert including direct communication, privacy, confidentiality and faster delivery of messages and receipt of responses. SMS messaging technology also allows the transmission of substantial numbers of messages simultaneously, hence reducing human resources and human errors.

\section{LITERATURE REVIEW}

Nowadays, the majority of university students owns at least one mobile phone. Students take mobile phones with them everywhere they go and use it on a daily basis. A recent report from [3], it stated that $66.8 \%$ of users use one mobile phone, $28.9 \%$ carry two mobile phones while $4.2 \%$ own more than two mobile phones. Generally, there is an increase in users who have a mobile phone.

Mobile phones especially smart phones are widely used to browse websites, do social networking and play online games, yet the important function of sending text messagesand making calls is still significant. A recent survey showed that over $65 \%$ of young adults (13-21 years old) in Malaysia have chosen text-based mobile communications as their most preferred way of communicating to others. In second place, $17 \%$ of the respondents preferred face-to-face communication while e-mail and phone calls had rates of preference of $10 \%$ and $8 \%$ respectively $[4]$.

Because of the high rate of SMS preference and usage, there is a great potential to utilize SMS reminders for developing an automated notification system to improve students' attendance in universities. The practice of sending SMS to alert parents on their children's attendance to class has been employed in several countries. This practice has lead to several 
benefits such as saving hours of time for academic and non-academic staff, increasing attendance rates, improving parent involvement, ensuring accurate reporting, helping the environment by reducing paper and ink usage and is more efficient than manually contacting parents.

Currently, there are many notification systems available in the market and several schools have utilized theses system to contact the parents personally by text messages or phone calls. In the California School District, an automated notification system which provides a two-way communication between schools and parents has been used to improve attendance from $90 \%$ to $95 \%$. This PhoneMaster technology is used not only to notify parents of student absenteeism, but also to keep parents updated about counseling and community services available [5-6]. Reports shown that students with involved parents are more likely to attend school regularly, produce better grades and have enhanced social skills [6].

Biometric technology is becoming increasingly prevalent in today's society. Fingerprint technology is by far the most commonly used modality followed by iris recognition [7]. Nowadays, many institutions are going down the biometric road to verify the time and attendance of their students and staff due to the security factors. Several researchers such as [8-10] have developed a similar attendance system using biometric (fingerprint) and Global System for Mobile Communications (GSM) to monitor students' attendance. This system is very easy to use and can generate a report based on fingerprints and SMS alerts are then sent to parents by means of GSM. Besides, only a small storage space is required for the biometric template, reducing the size of the database memory required and it is standardized.

Research conducted by [11] has produced a system that will record attendance automatically. In this project, a Web-Based Student Attendance System was developed using Radio Frequency Identification (RFID) technology. The ID cards of the students are embedded with RFID tag which is read by a reader. The system promotes a semi-automated approach in capturing student attendance, i.e. by having the students flash their student cards to the RFID reader. This system helps lecturers or teachers, to easily monitor their students' attendance online and this can improve the quality of teaching since less time is needed to manage student attendance records. Similar projects were also undertaken by [12-13].

Other than education system, the practice of SMS as a reminder is widely applied in the health 
care system to remind patients about the appointments made at the hospital. Various reminder systems have been trialed across a variety of clinical settings to reduce non-attendance rate. Several studies have shown that the use of SMS appointment reminders was effective in reducing non-attendance rates [14-15]. SMS reminders have also shown a significant saving of costs as it provides not only a cheap and automated alternative of sending out reminders, but also saves the administration staff time [16]. Therefore, it is recommended that the adoption of such systems will enhance the attendance not only in the medical setting but also increase attendance rates among students in schools, colleges and universities.

\section{OBJECTIVES OF THE STUDY}

Motivated by the background study from the literature where there were many claims mentioning the advantages of developing an automated system to send alerts via SMS, thus we would like to propose an automated system to manage and ease the current problem faced in managing students' attendance and sending notifications to students and guardians in UiTM. The main objective of this study is to develop an automated system which is capable:

- To smoothen the management report of the students' absenteeism to the class.

- To issue early notification by sending an SMS (and email) to the students and parents oncurrent status of absenteeism to the class.

Based on the objectives outlined above, we will name the system as Automated Attendance Management and Alert System (AAMAS).

\section{DEVELOPMENT}

In order to develop this project, we have used the Agile software development method which is an iterative model that is applicable to practical software development project. It involves iterative and incremental development which consists of multiple cycle of 1) Planning and Requirement Analysis, 2) Design, 3) Development, 4) Launching and Testing.

Prior to the development, a feasibility study was done in the preliminary stage of this project in order to determine whether the project is viable to be developed. We have made a general comparison in terms of the time, human resource and cost between the conventional system and the proposed system. We have learnt that by using the proposed system, we are able to 
reduce a significant amount of time in managing attendance record and sending notifications. Besides, the total cost that will be incurred by sending notifications via SMS and emails are much cheaper compared to by sending snail mail to students and guardians. Human resources can be reduced as well since the tedious task can be eased.

In what follows are the brief discussions on each of the stage performed during the system development.

\subsection{Planning and Requirement Analysis}

In this phase, we established the services that users require from the system to be developed and identified the requirements specifications as below:

1) All lecturers teaching any courses will be allowed to use the system.

2) Academic affairs department staff also will be granted access to use the system.

3) System's user can register the classes and upload the students' details with regard to the particular subject.

4) System's user can record the details of absenteeism for a particular student in the system (example of details: date of absenteeism, course code, week of the semester).

5) System should be able to calculate absenteeism percentages for all students automatically.

6) System should be able to list the students with high absenteeism record according to certain percentages.

7) System should be able to send notification or alert through SMS and email to respective students (with high absenteeism percentage rate).

8) System should be able to keep track of the number of notifications or alerts sent to respective students.

The new system will automatically send notifications via SMS and email to all students with absenteeism percentage of $7 \%, 10 \%$ and $15 \%$. The first $7 \%$ will be used to replace the verbal reminder practiced currently, while the $10 \%$ will be corresponding with the notification letter issued by Deputy Registrar (Academic). Finally, another reminder of 15\% absenteeism is provided to alert the students once more before they were asked to submit a show cause letter at $20 \%$ of absenteeism.

We have analyzed the data, software and hardware requirements to develop this system. The physical attendance form used in the conventional way of recording attendance in UiTM has 
been analyzed carefully to capture the type of important attributes.

Since as a start, we will be developing a stand-alone system which we believe is sufficient to be used by lecturers or staff at the Academic Affairs Division.Thus, we will be developing the system using Microsoft Visual Basic Ultimate 2012. Other software needed are MS Access that will be the database software and MS Excel which is needed to read students' data retrieved from the Students' Information Management System (SIMS).

\subsection{Design}

In the design phase, all the interfaces required for the system have been designed using MS Visual Basic Ultimate 2012. Some important interfaces are shown in the Results section. Besides the interfaces design, the database was also designed during this stage using MS Access. The design of all the tables were done according to the data specifications or attributes required which were determined in the previous stage. A comprehensive data dictionary for the purpose of development and future maintenance was also prepared during this stage. Fig. 1-8 present the field name and data types in each table constructed according to the data dictionary.

\begin{tabular}{ll}
\multicolumn{1}{c}{ Field Name } & \multicolumn{1}{c}{ Data Type } \\
UserName & Short Text \\
\hline Password & Short Text \\
\hline StaffID & Short Text \\
\hline
\end{tabular}

Fig.1. Table User to store users' login data

\begin{tabular}{|l|l|}
\hline \multicolumn{1}{|c|}{ Field Name } & \multicolumn{1}{c|}{ Data Type } \\
\hline StaffID & Short Text \\
\hline ICNumber & Short Text \\
\hline Name & Short Text \\
\hline Registered & Short Text \\
\hline
\end{tabular}

Fig.2. Table User-Info to store users' particulars data 


\begin{tabular}{|l|l|}
\hline \multicolumn{1}{|c|}{ Field Name } & \multicolumn{1}{c|}{ Data Type } \\
\hline CourseCode & Short Text \\
\hline ClsGroup & Short Text \\
\hline NoOfWeeks & Short Text \\
\hline NoOfClassesPerWeek & Number \\
\hline Class1 & Number \\
\hline Class2 & Number \\
\hline Class3 & Number \\
\hline Class4 & Number \\
\hline Class5 & Number \\
\hline TotalHoursPerWeek & Number \\
\hline
\end{tabular}

Fig.3. Table Class-Registration to store classes registration data

\begin{tabular}{|ll|}
\hline \multicolumn{1}{c|}{ Field Name } & \multicolumn{1}{c|}{ Data Type } \\
\hline StudentID & Short Text \\
\hline Name & Long Text \\
\hline Mode & Short Text \\
\hline Programme & Short Text \\
\hline Part & Short Text \\
\hline NoTaken & Short Text \\
\hline CourseCode & Short Text \\
\hline PhoneNumber & Short Text \\
\hline Group & Short Text \\
Email & Short Text \\
\hline
\end{tabular}

Fig.4. Table Students-Particulars to store students' data

\begin{tabular}{|l|l|}
\hline \multicolumn{1}{|c}{ Field Name } & \multicolumn{1}{c}{ Data Type } \\
\hline StudentID & Short Text \\
\hline Name & Long Text \\
\hline Week & Number \\
\hline Class & Short Text \\
\hline AbsentDate & Short Text \\
Hour & Number \\
\hline CourseCode & Short Text \\
\hline Group & Short Text \\
\hline
\end{tabular}

Fig.5. Table Attendance to store attendance data

\begin{tabular}{|l|l|}
\hline \multicolumn{1}{|c|}{ Field Name } & \multicolumn{1}{c|}{ Data Type } \\
\hline StudentID & Short Text \\
\hline Name & Long Text \\
\hline Percentage & Number \\
CourseCode & Short Text \\
Group & Short Text \\
\hline
\end{tabular}

Fig.6. Table Absentees to store absentees' data

\begin{tabular}{|l|l|}
\hline \multicolumn{1}{|c|}{ Field Name } & \multicolumn{1}{c|}{ Data Type } \\
\hline StudentID & Short Text \\
StudentName & Short Text \\
\hline CourseCode & Short Text \\
\hline Group & Short Text \\
\hline Percentage & Short Text \\
\hline MessageCounter & Number \\
\hline 7Percent & Short Text \\
\hline 1OPercent & Short Text \\
\hline 15Percent & Short Text \\
\hline
\end{tabular}

Fig.7. Table SMS-Status to store alerts status of respective students 


\begin{tabular}{|l|l|}
\hline \multicolumn{1}{|c|}{ Field Name } & \multicolumn{1}{c|}{ Data Type } \\
\hline User & Short Text \\
\hline PhoneNumber & Short Text \\
\hline Date & Short Text \\
Balance & Short Text \\
\hline
\end{tabular}

Fig.8. Table User-SMSBlastRecord to store SMS blast record and credit balance for user In order to show the correlations among the designed tables, Fig. 9 illustrates the links among the tables constructed.

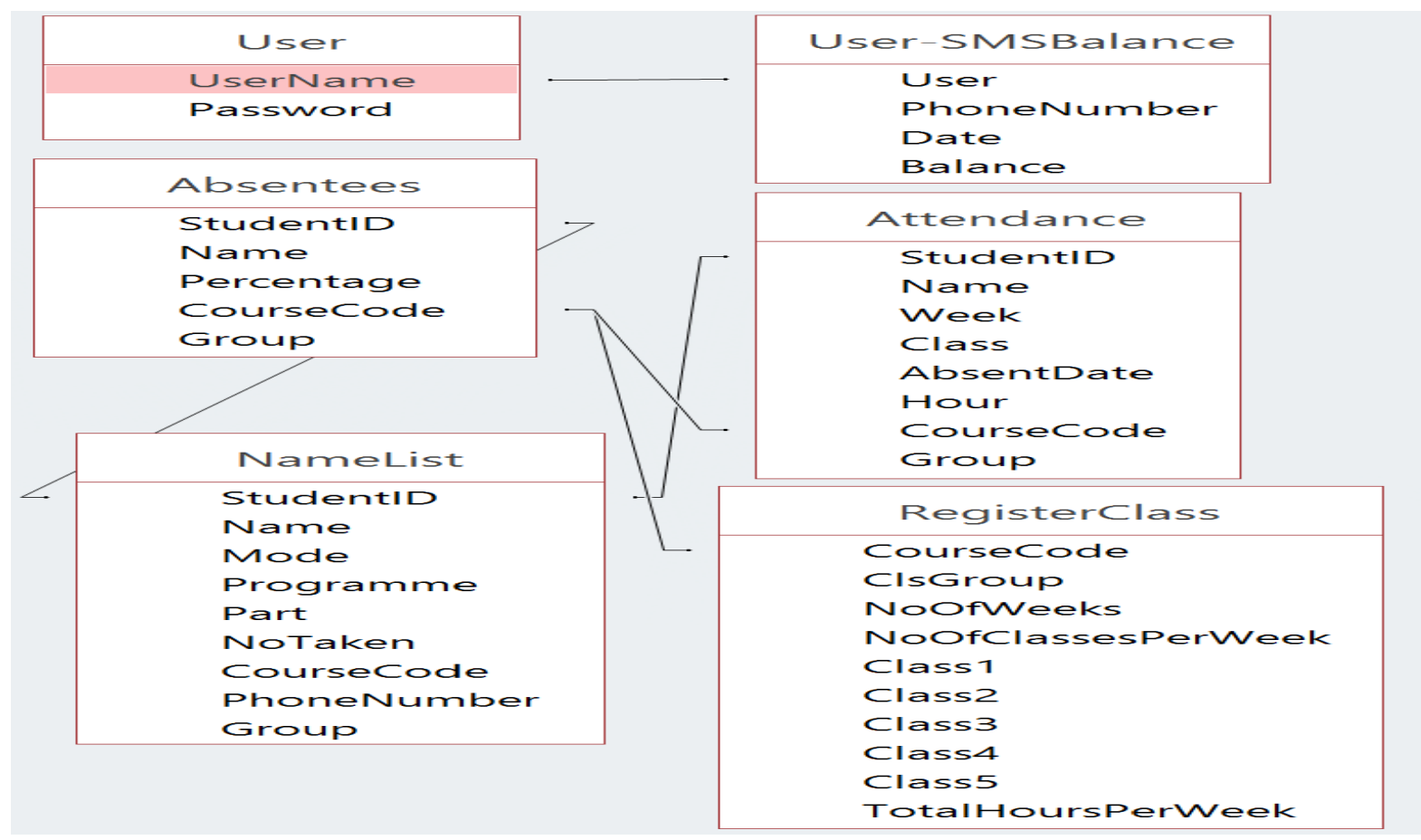

Fig.9. Relationships among the tables constructed in the database

System architecture for the proposed system also has been carefully designed as illustrated in Fig. 10.
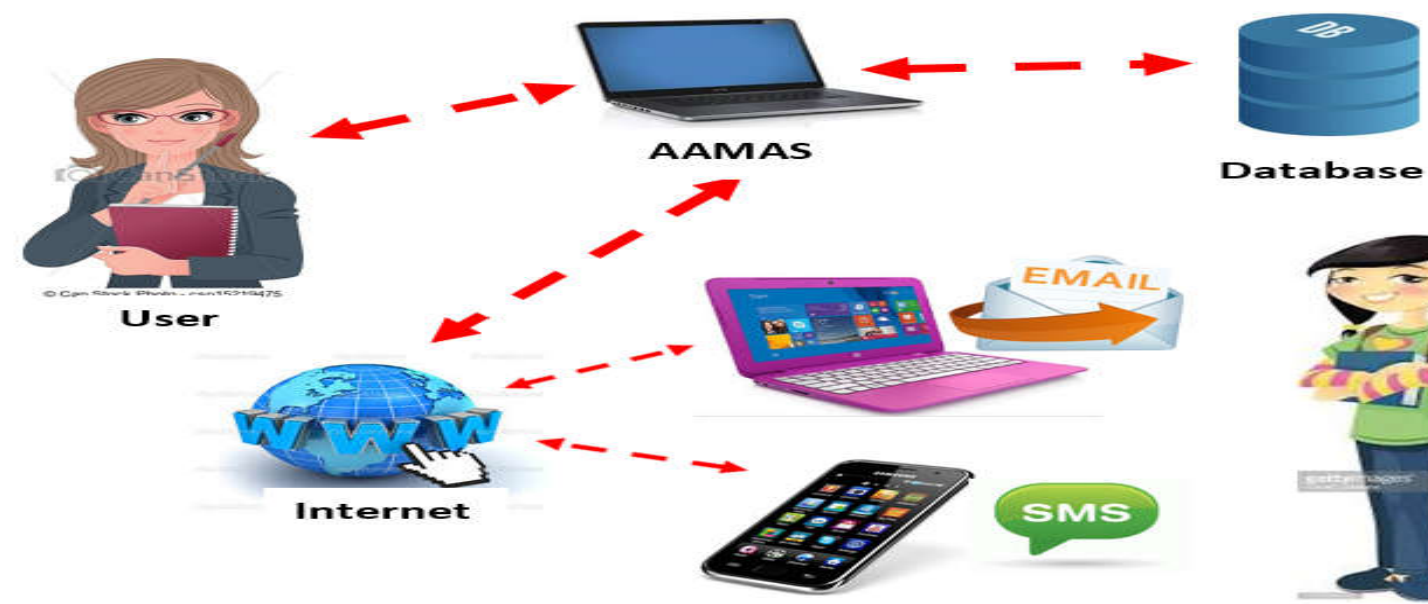

Fig.10. System architecture for AAMAS 


\subsection{Development}

AAMAS was developed on Windows 7 platform by using MS Visual Basic Ultimate 2012. All the modules were programmed according to the pseudocodes design in the previous phase. During development, the integration among MS Visual Basic 2012, MS Access and MS Excel were done and it was observed that the integrations were compatible.

\subsection{Launching and Testing}

In this stage, each unit and module was tested to evaluate whether it was functioning properly as expected. The testing was done with two goals in mind: i) to validate whether the system operates as intended, ii) to discover any faults or defects in any part of the systems. The tests include the linking between the interfaces, connections to the database, retrieval of user information, registration of classes, recording of absenteeism data, calculations of absenteeism percentage, blasting of SMS and emails and the CRUD (Create, Retrieve, Update and Delete) functions for some modules. Below are outcomes of the testing phase performed:

\subsubsection{Validation Testing}

All the requirements specifications as obtained in the previous phase were checked carefully during the validation testing to ensure the system conforms to all specifications. Each item tested and the validated status can be seen in Table 1. 
Table 1. List of requirements and validation status

\section{Item Tested}

Validated Status

All lecturers teaching any courses will be allowed to use the system.

Yes

Academic affairs department staff also will be granted access to use the

Yes system.

System's user can register the classes and upload the students' details

Yes with regard to the particular subject.

System's user can record the details of absenteeism for a particular Yes student in the system (example of details: date of absenteeism, course code, week of the semester).

System should be able to calculate absenteeism percentages for all Yes students automatically.

System should be able to list the students with high absenteeism record Yes according to certain percentages.

System should be able to send notification or alert through SMS and email to respective students (with high absenteeism percentage rate).

System should be able to keep track of the number of notifications or alerts sent to respective students.

\subsubsection{Defect Testing}

In order to discover any faults or defects in the AAMAS system as mentioned previously, defect testing was also performed. Through the testing done, one defect was exposed in the system in which a class group code which consists of 10 numerical characters failed to be recognized by the system. Failing to do so has resulted in no students' names with regard from the selected class were listed which disabled the user from updating the respective students' attendance record. Fig. 11 illustrates the defect. 


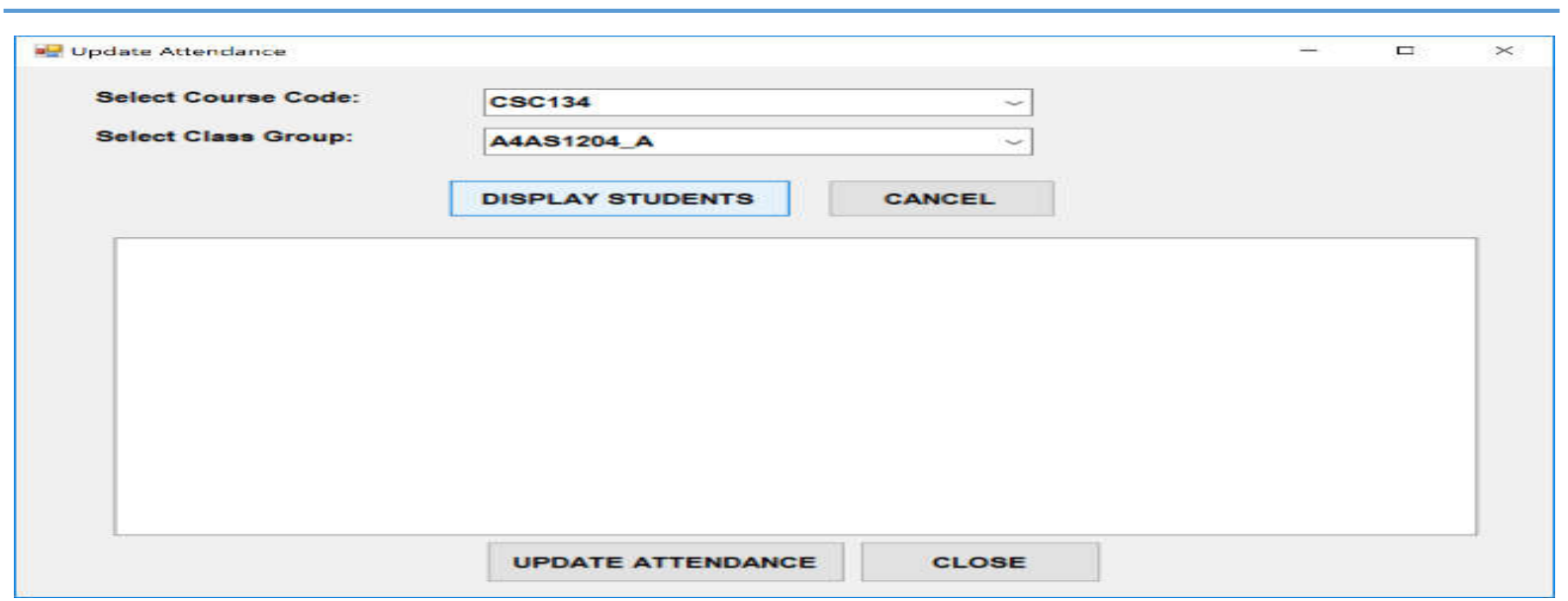

Fig.11. Interface illustrating students' names were not displayed due to system defect

Realizing the defect was originated from incompatible data which the system is not able to cater due to the initial design, we have redesign the table involved in the database to accommodate the data. Previously the maximum character for the class group code field in the database was only nine (the common length for class group code in UiTM). However, recently new format of class group code in which " "” (underscore character) was used resulting in an increased from nine characters to ten characters long. To resolve the defect, we have updated the length for the field from nine characters to ten characters long. After fixing the problem, we have done the testing again, and it was shown that the system is now able to recognize the class group code with the underscore character (10 characters long) as can be seen in Fig. 12.

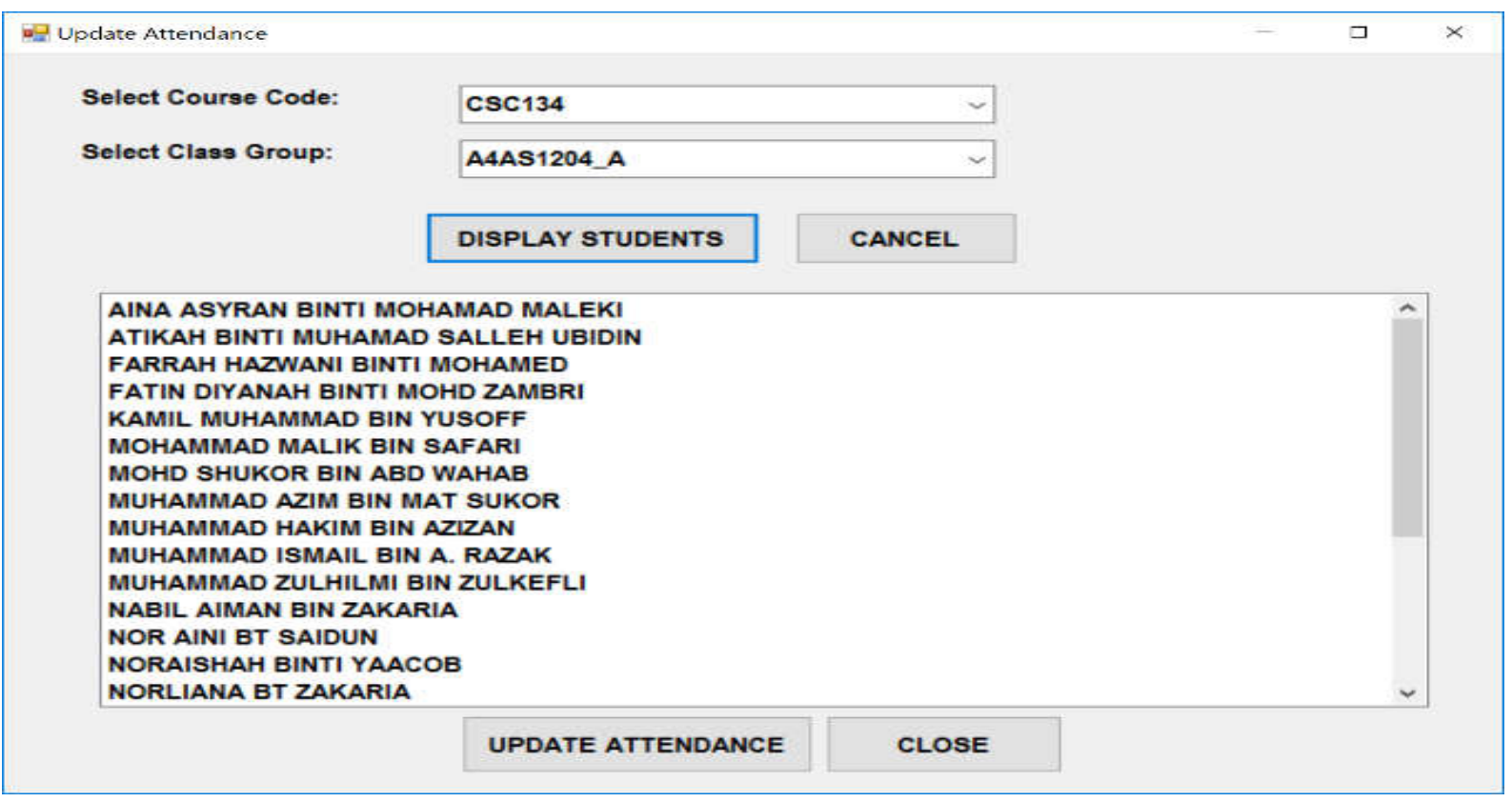

Fig.12. Interface illustrating students' names were now displayed after defect was fixed 


\section{RESULTS AND DISCUSSION}

We have run AAMAS on a few sets of data (different groups of students and classes) to test the functionality of the system. Fig. 13 illustrates the system flow for AAMAS. We proceed next by discussing the results based on its graphical user interfaces [17] and performance evaluation.

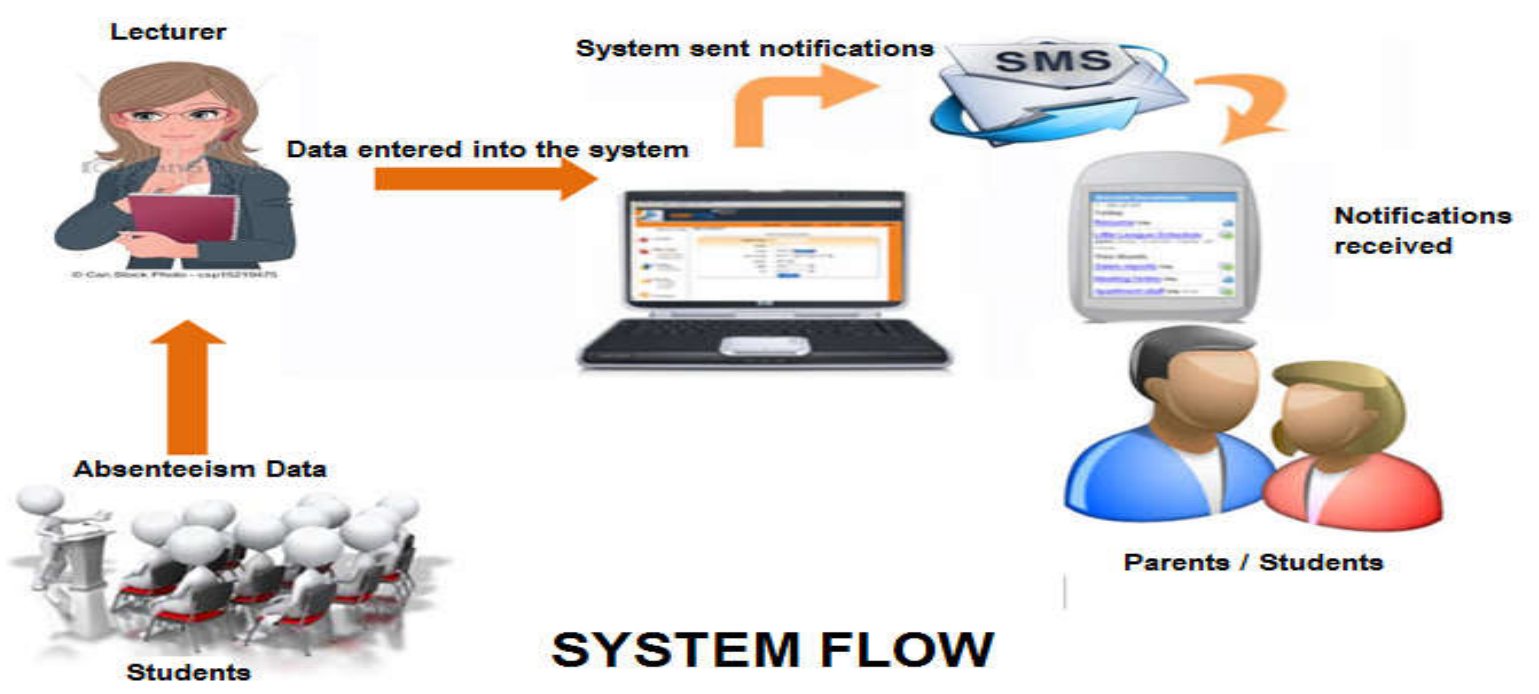

Fig.13. System flow for AAMAS

\subsection{Graphical User Interface}

This section discusses the main menu offered in AAMAS as portrayed in Fig. 14. The following table presents the menu of the graphical user interface (GUI) [18] and the function of each menu.

Table 2. Summary of main menu and its functions

\begin{tabular}{ll}
\hline \multicolumn{1}{c}{ Menu } & Function \\
\hline Check Balance & $\begin{array}{l}\text { Displays the current balance of credits available to send notifications } \\
\text { via SMS. }\end{array}$ \\
Register Class & Allows the user to register classes' information in the system which \\
& consists of the Course Code, Class Group, Number of Weeks, Number \\
& of Classes Per Week and Number of Hours for Each Class in the Week \\
& (see Fig. 15). \\
& Allows the user to upload students' data in the MS Excel file. The \\
& system then reads the data from the spreadsheet file and will \\
& automatically stores the data in the database (see Fig. 16-18).
\end{tabular}




\begin{tabular}{|c|c|}
\hline $\begin{array}{l}\text { Update } \\
\text { Attendance }\end{array}$ & $\begin{array}{l}\text { Allows the user to update the students' attendance by entering } \\
\text { absenteeism information by just a few easy clickings (see Fig. 19). }\end{array}$ \\
\hline $\begin{array}{l}\text { Generate } \\
\text { Report }\end{array}$ & $\begin{array}{l}\text { System will calculate percentage of absenteeism automatically for all } \\
\text { students. Another list indicating students with high percentage of } \\
\text { absenteeism will be generated (see Fig. 20). }\end{array}$ \\
\hline $\begin{array}{l}\text { Blast SMS and } \\
\qquad \text { Email }\end{array}$ & $\begin{array}{l}\text { System will automatically send notifications via SMS and email to all } \\
\text { students with absenteeism percentage of } 7 \%, 10 \% \text { and } 15 \% \text {. Each time } \\
\text { a notification being sent out, the system is capable to keep track on the } \\
\text { number of notifications (see Fig. } 21-23 \text { ). }\end{array}$ \\
\hline \multicolumn{2}{|c|}{ Automated Attendance Management and Alert System } \\
\hline & \begin{tabular}{|c|} 
Change Password \\
Check Balance \\
Register Class \\
Upload File \\
Update Attendance \\
Generate Report \\
Blast smis and Emall \\
Exit \\
\end{tabular} \\
\hline
\end{tabular}

Fig.14. Screen illustrating the main menu for AAMAS

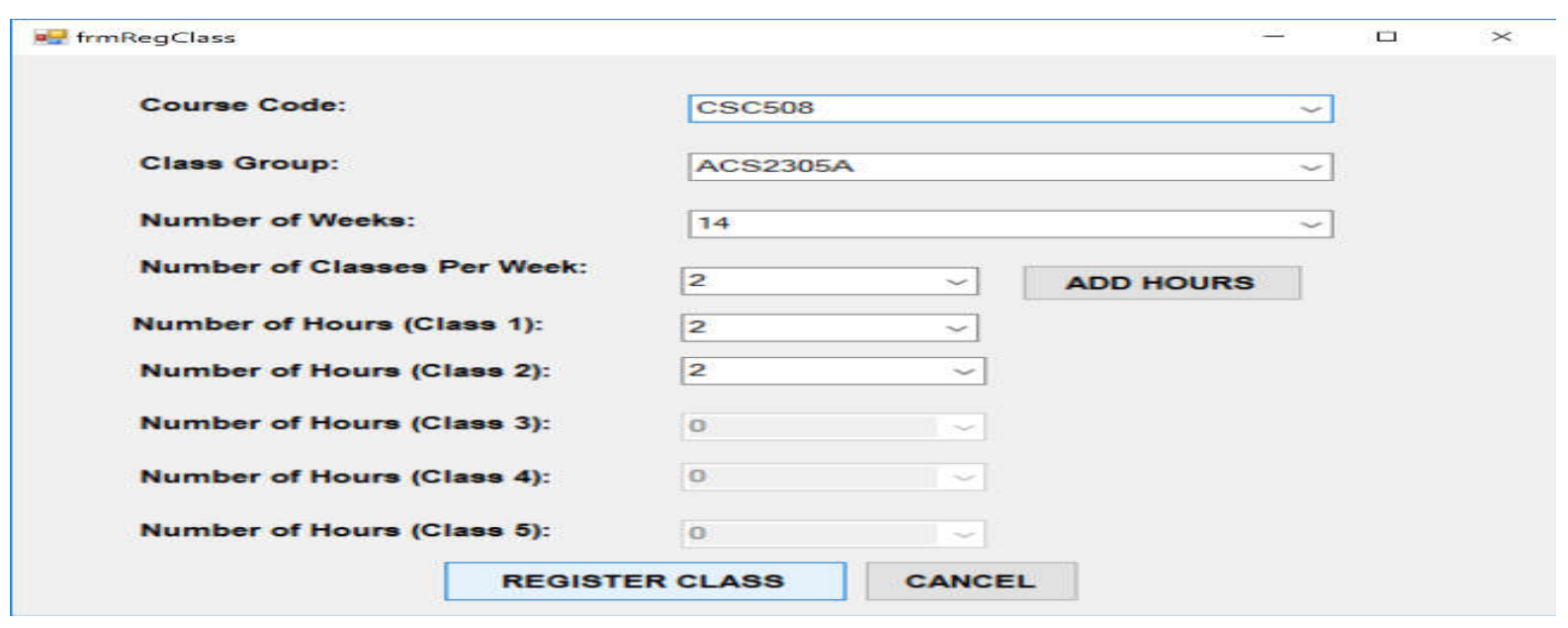

Fig.15. Screen for registering class information 
ale frmuploadilo

Upload Students Name List File Here: Browse $\square$ Showms Excelfile

File Selected: SILVERIFrom Documents HP ProBook-SilverIKIKLACS2303ACSC463.xIs

Upload Cancel

Fig.16. Screen for uploading file

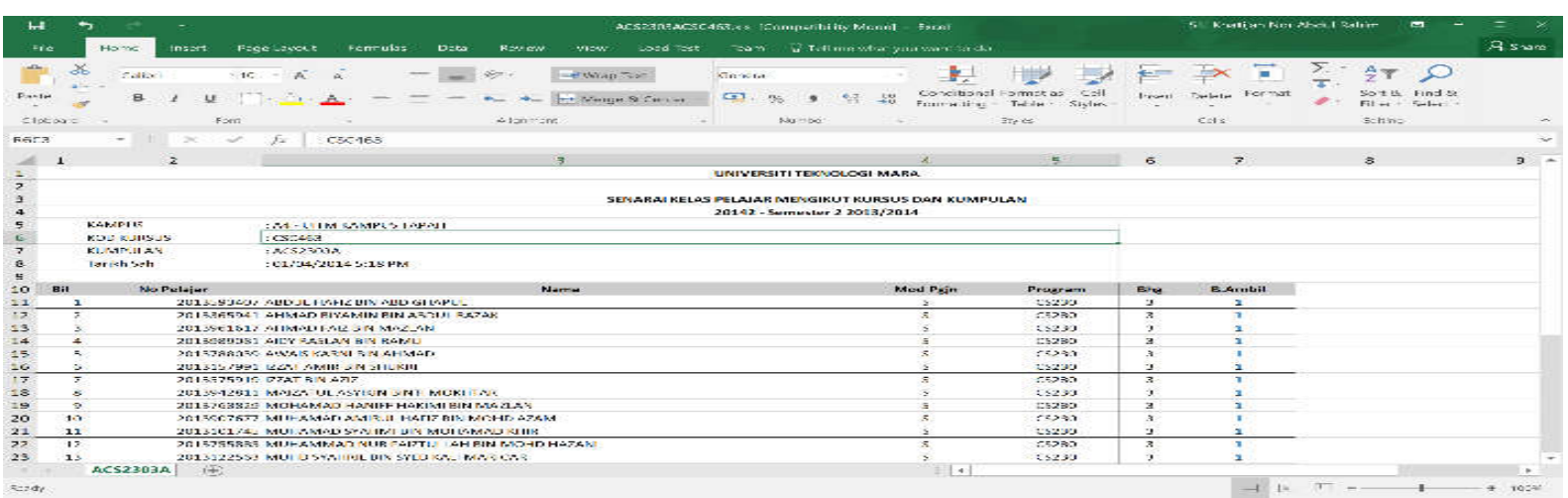

Fig.17. Example of spreadsheet file containing students' information

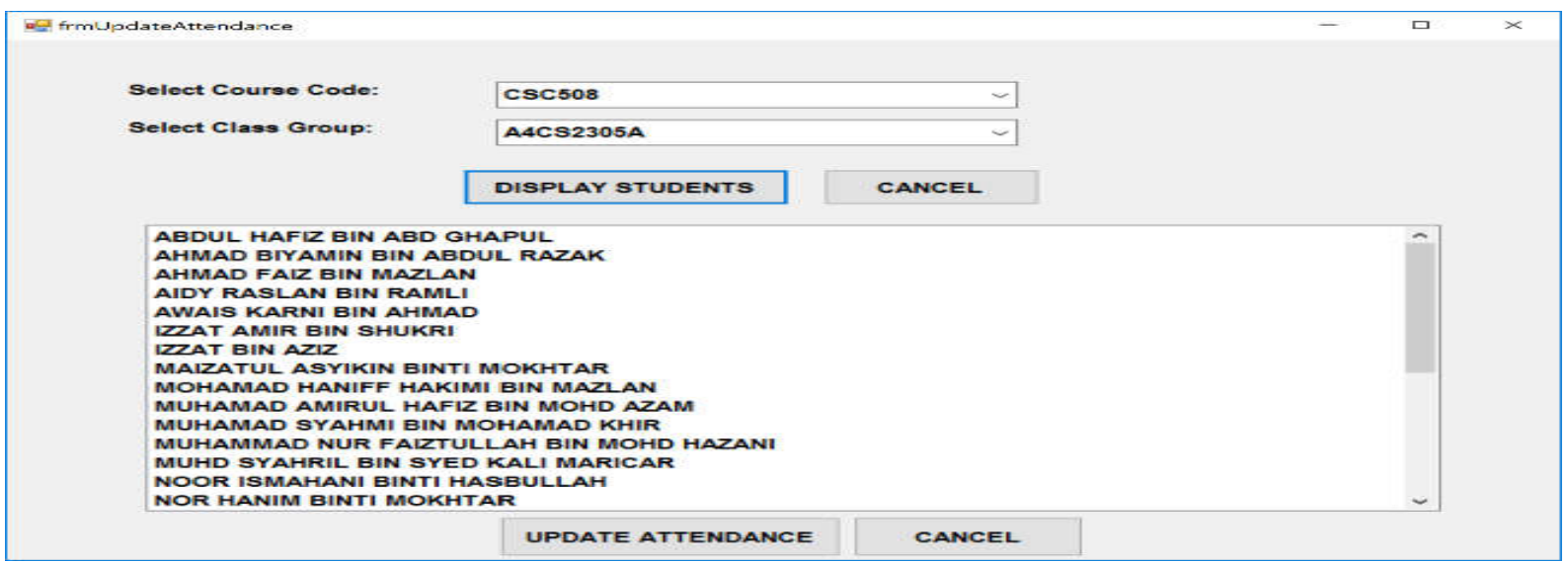

Fig.18. List of students' names

al frmupdateAttendance 2

STUDENT NAME: ALIFF SHUAIB BIN RAZAK

STUDENT ID: 2013876755

ABSENTEES INFORMATION:

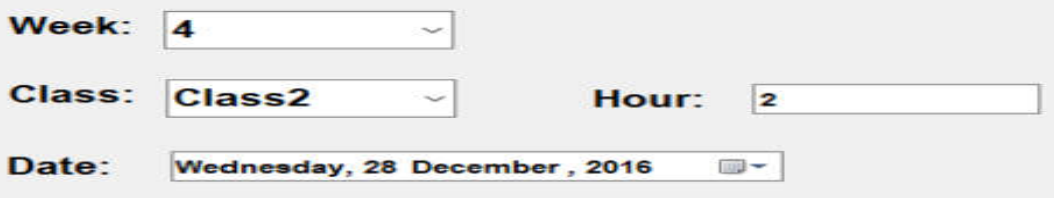

BACK UPDATE CANCEL

Fig.19. Screen for updating absenteeism information 


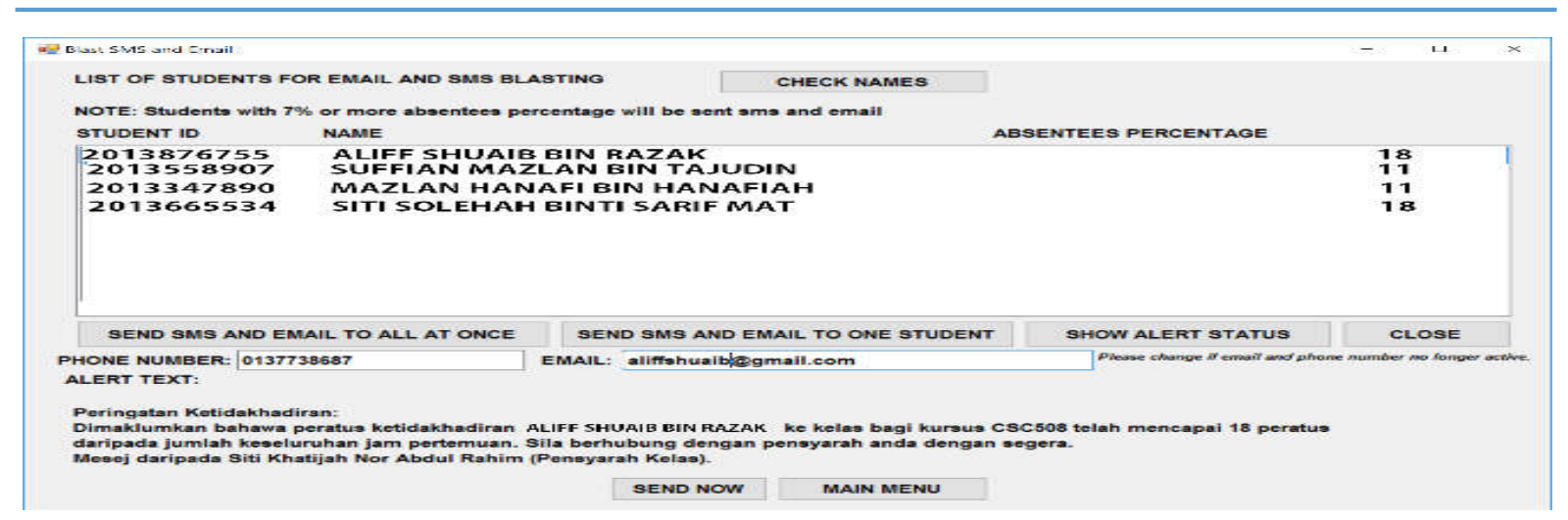

Fig.20.Screen containing list of students with high absenteeism percentage

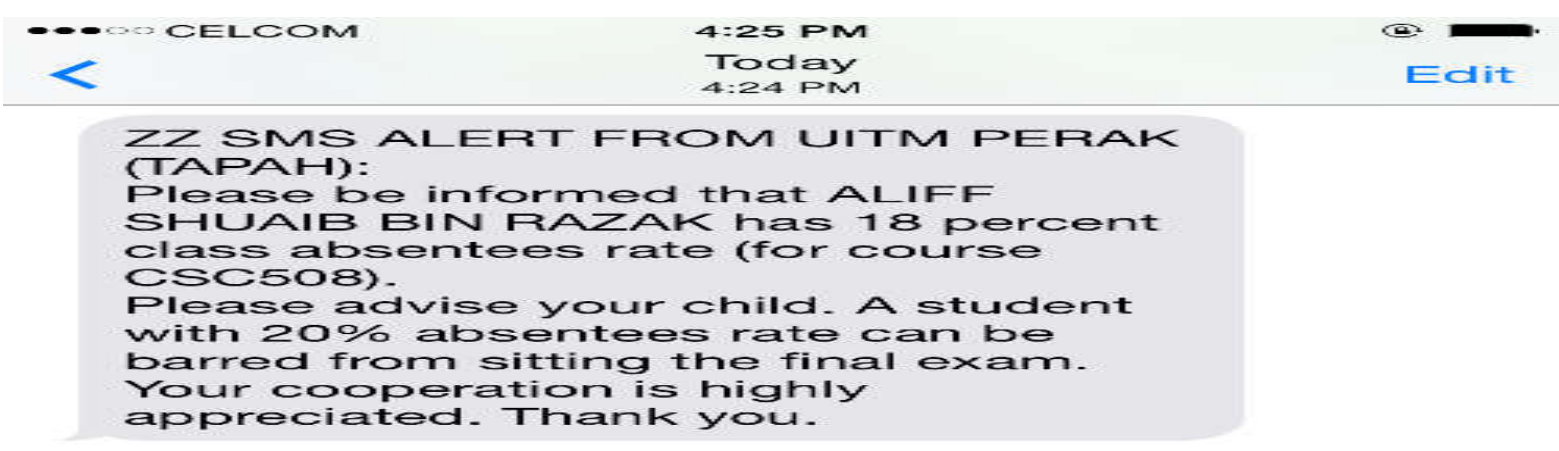

Fig.21. Screen containing list of students with high absenteeism percentage 


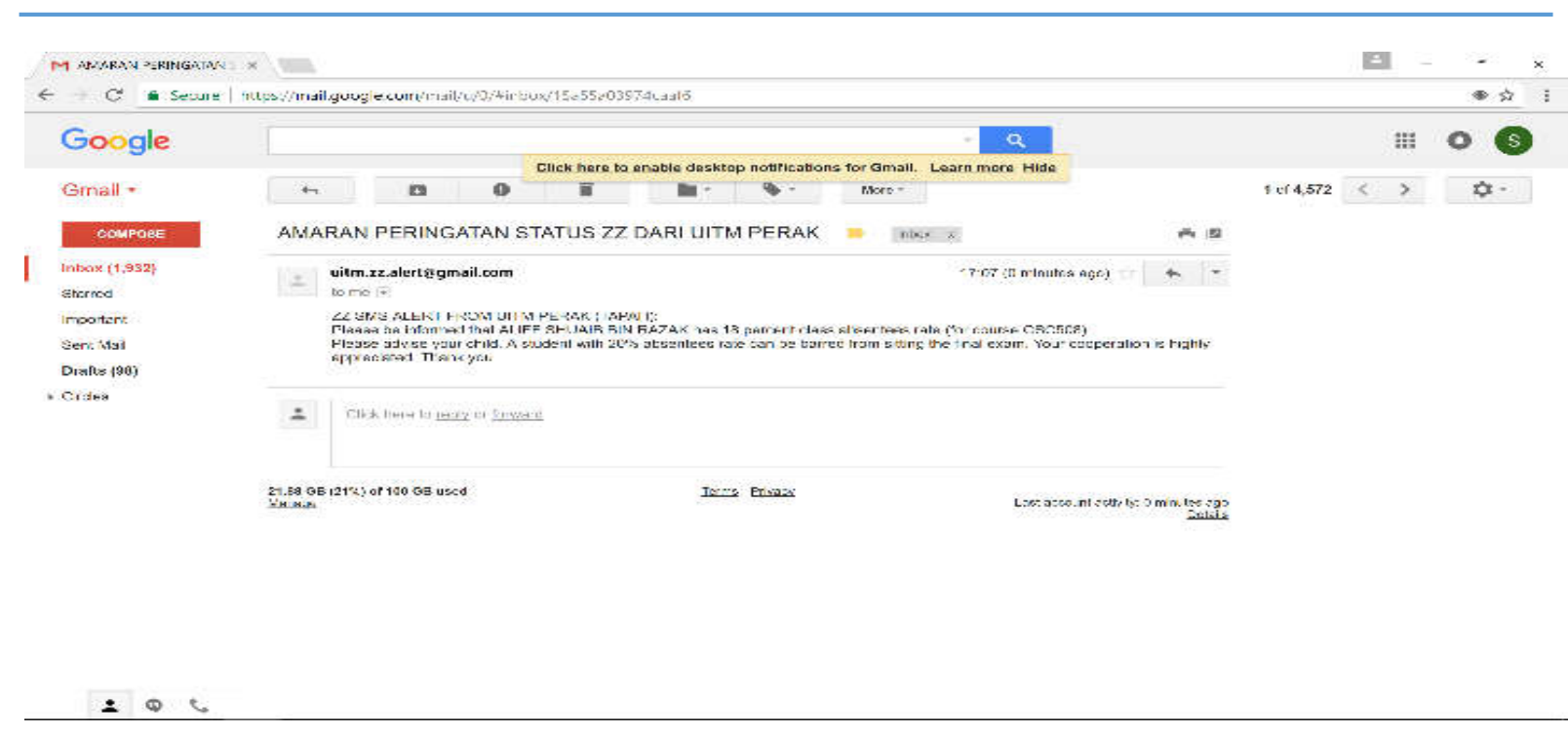

Fig.22. Example of email received by students

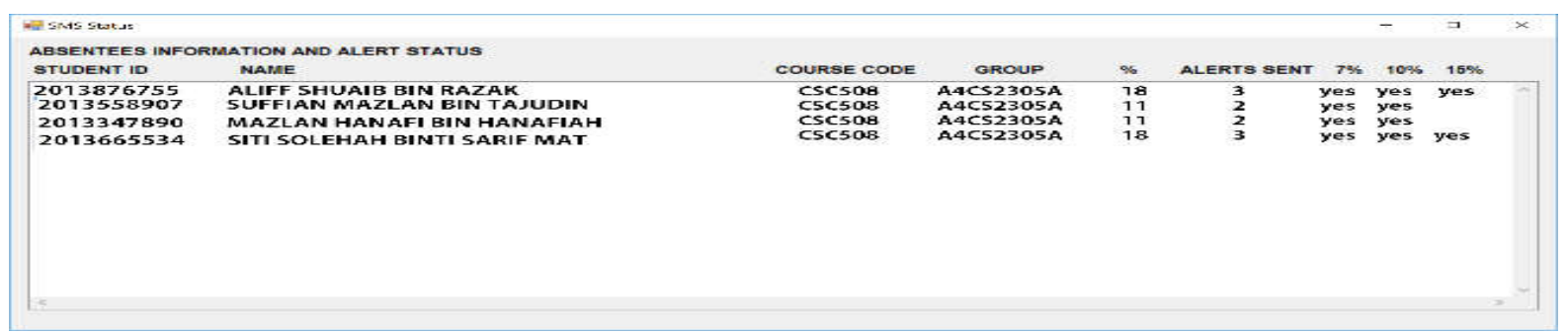

Fig.23. Screen showing system is capable in tracking the number of alerts sent

\subsection{Findings Based on Performance Evaluations}

The system has been observed to be very simple, user friendly, straightforward and stable to be used. All the modules developed in the system were running correctly and efficiently. The functions provided by the system were able to assist the user in managing the students' attendance record efficiently. AAMAS managed to calculate the absenteeism record for each student in the system and determined the students with high absenteeism percentage. The system then sent notifications alert automatically to the students to remind them on their high absenteeism rate via SMS and email. The system can also send notifications to guardians, academic advisors and other parties too if it is needed. Each time alert is being sent out, the system recorded it in and therefore enable users to keep track on the number of alerts being sent. The minimal time taken to produce the report on the absenteeism percentage and to send alert notifications were observed to be the advantages of the proposed system which managed to outperformed the existing conventional system.

in Table 3, we present the differences of the approximate time taken for some important 
procedures or processes by using the AAMAS system as opposed to the conventional system.

Table 3. Procedures and comparisons of time taken to perform using manual VS AAMAS

\begin{tabular}{|c|c|c|}
\hline Procedure & $\begin{array}{l}\text { Approximate Time } \\
\text { Taken Using } \\
\text { Manual System }\end{array}$ & $\begin{array}{c}\text { Approximate } \\
\text { Time Taken Using } \\
\text { AAMAS System }\end{array}$ \\
\hline $\begin{array}{l}\text { Calculate Students' Absenteeism } \\
\text { Percentages for One Student }\end{array}$ & 300 seconds & 1 second (or less) \\
\hline $\begin{array}{l}\text { Calculate Students' Absenteeism } \\
\text { Percentages for One Class }\end{array}$ & 1800 seconds & 1 second (or less) \\
\hline $\begin{array}{l}\text { Time to Prepare Warning Letter / } \\
\text { Notifications for One Student with High }\end{array}$ & 600 seconds & 1 second (or less) \\
\hline Absenteeism Percentage & & \\
\hline $\begin{array}{l}\text { Time to Prepare Warning Letter / } \\
\text { Notifications for One Class for Students } \\
\text { with High Absenteeism Percentage }\end{array}$ & 3000 seconds & 1 second (or less) \\
\hline $\begin{array}{l}\text { Duration of Warning Letter or } \\
\text { Notifications Received by Students from } \\
\text { the Time Sent }\end{array}$ & $\begin{array}{l}259,200 \text { seconds } \\
\text { ( } 3 \text { days })\end{array}$ & 30 seconds (or less) \\
\hline
\end{tabular}

Based on Table 3, it was observed that the time taken to complete the whole process from calculating absenteeism percentage until the notification has been received by a particular student is much less in comparison to using the manual system. Only 2 seconds are needed, whereas as much as 900 seconds are needed by using a manual system for calculating and preparing letter to a student. In terms of the duration taken in receiving a letter or SMS from the time it was sent, only 30 seconds approximately are needed, whereas as much as 259,200 seconds are needed by using a manual system. Thus, a significant amount of time can be saved by using the proposed AAMAS thus increasing the productivity and throughput of the process.

We have also examined the cost incurred by using the proposed system (AAMAS) in terms of sending notifications to students using SMS as opposed to sending snail mail. Interestingly, it was observed that the cost for sending an SMS is cheaper as compared to sending the snail mail. Below we present the comparison of the costs. 
Table 4. Cost comparisons table for snail mail versus SMS

\begin{tabular}{ccc}
\hline Medium of notifications & Snail Mail & SMS \\
\hline Approximate cost per letter or SMS & RM0.80 & RM0.05
\end{tabular}

According to Table 4, it can be clearly seen that the cost per SMS is just RM0.05 for a student which is cheaper as compared to the cost per letter sent using snail mail, in which an approximately of RM0.80 in total is incurred. This indicate that the AAMAS is more effective in cost reduction by more than $93 \%$. In order to send a letter, the cost of papers, envelope and stamp must be taken into considerations, thus contributing to a higher cost. On the other hand, for sending an SMS, the cost is quite low since most of the SMS service providers are offering certain packages, in which buying SMS credit in bulks would be less expensive. Based on our survey, if SMS credit is purchased in bigger bulks, one SMS cost can be reduced to as low as RM0.01. Therefore, RM0.79 can be saved for each student by using AAMAS. This will definitely be an advantage to the university in saving costs, if AAMAS is used as an alternative to the manual system.

On top of the observations made, we have also made an analysis on the total time and money saved by using AAMAS. Table 5 illustrates the analysis of savings for 1 student, 3 students and $1 \%$ of total UiTM students per semester (1\% x 165,028 students).

Table 5.Analysis of total time and money saved by using AAMAS

\begin{tabular}{ccc}
\hline Number of Students & Total Time Saved & Total Money Saved \\
\hline 1 & 260,068 seconds & RM0.79 \\
3 & 780,204 seconds & RM2.37 \\
1650 & $429,112,200$ seconds & RM1303.50 \\
\hline
\end{tabular}

From the analysis, for the purpose of estimating the amount of time and money that could be saved by using AAMAS, we assume the number of absenteeism per semester is about $1 \%$ of the overall UiTM students throughout Malaysia. So, 1\% out of 165, 028 total students (current number of total UiTM students throughout Malaysia), the approach would save RM2607 and 858, 224, 400 seconds per year not including the amount of savings obtained by reducing staff time on the manual process.

\section{CONCLUSION}

In this paper, we have discussed about a system which we have developed the Automated Attendance Management and Alert System (AAMAS) with the objectives to manage and ease 
the current problem faced in managing students' attendance and sending notifications to students and guardians in UiTM. The idea in producing AAMAS is aligned with the development of the SMS notification system as a reminder that is widely used in various fields. This system was developed using MS Visual Basic, MS Access and MS Excel software using the Agile software development method.

By using the proposed system, it was observed that the process of managing students' attendance and calculating students' absenteeism percentages were no longer a hassle since all were eased by having such automated system. The late notifications received by students and guardians previously managed to be solved efficiently since AAMAS can automatically send SMS and email to remind them on high absenteeism percentage to class. Interception of letters to the guardians can also be eliminated. Notwithstanding the advantages offered by AAMAS, this system is able to track the number of alerts being sent, thus assists the users in having the updated status of the notifications delivery. Through this automated system, significant amount of time and money can be saved too, for instance time needed to fill out forms and issue notification letters manually to guardians can be minimized significantly. Besides, message interception, human resources and human errors can also be reduced. In the future, this system can be further enhanced to cater for different format of data file and specifications. It also has the potential to be commercialized to any universities and learning institutions throughout Malaysia.

\section{ACKNOWLEDGEMENTS}

The authors would like to thank UniversitiTeknologi MARA, Tapah Campus for the computing facilities that make the system possible to be developed. Thank you also to lecturers and staff who have participated in the survey and supported our work and whoever who has involved and contributed directly or indirectly in making this study a success.

\section{REFERENCES}

[1] Girau E A, Benedict M, Joseph A Y. The effect of class absenteeism on students performance: Evidence from Faculty of Accountancy UITM Sabah. Research reports, Selangor: Research Management Institute, UniversitiTeknologi MARA, 2011 
[2] UniversitiTeknologi MARA (UiTM). PekelilingAkademikBil 2/2012-Penyelarasan pelaksanaanpemberian status ZZ kepadapelajar. Selangor: UiTM, 2012

[3] Malaysian Communications and Multimedia Commission (MCMC). Hand phone users survey 2014. Selangor: MCMC, 2015

[4] eMarketer. In Malaysia and Vietnam, chat apps and texting rule communications: Young people in Southeast Asia would prefer not to actually hang out with friends. 2015, http://www.emarketer.com/Article/Malaysia-Vietnam-Chat-Apps-Texting-Rule-Communicati ons/1012947

[5] Warren P. Automated notification system improves Calif. School district's crisis management, attendance. THE Journal (Technological Horizons in Education), 2004, 31(39):39

[6] Villano M. Meet the parents: Notification tools can do more than alert the school community to an emergency. New systems are cultivating parental involvement by sending home daily reports on students' behavior, attendance, and performance. THE Journal (Technological Horizons in Education), 2008, 35(4):48

[7] Nelson M, Wright T, Ashida K. Fujitsu's PalmsSecure-based e-POS system for school cafeteria. Fujitsu Scientific and Technical Journal, 2007, 43(2):236-244

[8] Jaikumar K, Kumar M S, Rajkumar S, Sakthivel A. Fingerprint based student attendance system with SMS alert to parents. International Journal of Research in Engineering and Technology, 2015, 4(2):293-297

[9] Dandge P R, Kharat II, Hire A N, Farpat S L. Attendance monitoring using biometrics by GSM technology. International Journal of Engineering, Education and Technology, 2015, $3(2): 1-9$

[10]Indico M H, Lanciso L M, Vargas A L. Mobile monitoring and inquiry system using fingerprint biometrics and SMS technology. International Journal of Scientific and Research Publication, 2014, 4(1):1-6

[11]Mohammed AA, Jyothi K U. Web-server based student attendance system using RFID technology. International Journal of Engineering Trends and Technology,2013, 4(5):1559-1563

[12]Zhi M, Mahinderjit S M. RFID-enabled smart attendance management system. InJ. Park, 
Y. Pan, C. Kim, \& Y. Yang (Eds.), Future information technology-II. Lecture Notes in Electrical Engineering. Dordrecht: Springer, 2015, pp. 213-231

[13]Arulogun O T, Olatunbosun A, Fakolujo O A, Olaniyi O M. RFID-based students attendance management system. International Journal of Scientific and Engineering Research, 2013, 4(2):1-9

[14]Foley J, O’Neill M. Use of mobile telephone short message service (SMS) as a reminder: The effect on patient attendance. European Archives of Paediatric Dentistry, 2009, 10(1):15-18

[15] Youssef A, Alharthi H, Al Khaldi O, Alnaimi F, Alsubaie N, Alfariss N. Effectiveness oftext message reminders on nonattendance of outpatient clinic appointments in three different specialties: A randomized controlled trial in a Saudi Hospital. Journal of Taibah University Medical Sciences, 2014, 9(1):23-29

[16] McClean S, Perera M. The use of short message service (SMS) for patient appointment reminders. Journal of Mobile Technology in Medicine, 2012, 1(3):53-55

[17]Miskon M T, Rizman Z I, Chek W A, Fauzi F D. Fitness cycling device with graphical user interface based on IEEE 802.15. 4 transceiver for real time monitoring. Journal of Applied Environmental and Biological Sciences, 2014, 4(12):108-114

[18]Fauzi F D, Mulyana T, Rizman Z I, Miskon M T, Chek W A, Jusoh M H. Supervisory fertigation system using interactive graphical supervisory control and data acquisition system. International Journal on Advanced Science, Engineering and Information Technology, 2016, $6(4): 489-494$

\section{How to cite this article:}

Rahim S. K. N. A, Ismail N. R. P., Razak F. A., Zulkifli I. Z., Jamian N. H., Razi N. F., Mohammad N. H. Automated Attendance Management and Alert System. J. Fundam. Appl. Sci., 2017, 9(6S), 59-80. 